EPiC Series in Language and Linguistics
Volume 2, 2017, Pages 143-147
Professional and Academic Discourse:
an Interdisciplinary Perspective

\title{
Strategies for Teaching Unbiased Language in English for Law Enforcement
}

\author{
Gabriela Torregrosa and Sonsoles Sánchez-Reyes \\ Universidad de Salamanca, Spain \\ gabriela.torregrosa@usal.es, sreyesp@usal.es
}

\begin{abstract}
The EU Charter of Fundamental Rights (2000) forbids discrimination, and national legislations follow suit. Language is a symptom of and a contributor to an unequal status. Civil servants, and the police to a higher extent, must observe this in order to prevent secondary victimisation and contribute to attitudes of inclusion and equal opportunities. Therefore, training in non-discriminatory language is a must in any EFL course for law enforcers.

Different teaching methodologies are applied with trainee police officers (CEFR B1) in the Spanish Police Academy to obtain critical language awareness. These strategies allow trainee officers to produce discourse sensitive to difference, and have beneficial results in building up their linguistic proficiency addressed to their professional performance.
\end{abstract}

\section{Introduction}

The EU Charter of Fundamental Rights (2000, art. 21.1) forbids discrimination and promotes equal opportunities, and national legislations of most countries follow suit. Language is both a symptom of and a contributor to an unequal status.

The minority groups who are affected by biased language are identified mostly by their gender, social class, race and ethnicity, religion, sexual orientation, ideological background, disabilities and old age (Nguyen, 2007). Civil servants, and the police to a higher extent, must observe this in order to prevent secondary victimisation and contribute to attitudes of inclusion and equal opportunities. Therefore, training in non-discriminatory language is a must in any EFL course for law enforcers and should be taken very seriously.

Political correctness is expressed by both a range of new terms and new meanings applied to established words (Hughes, 2007). It is possible to eliminate the prejudices inherent to cultural, sexual and racist stereotypes with culturally neutral and value-free terms (Davies, 2007), and ESP learners from police forces must engage in awareness raising activities designed to sensitize them in this respect.

Traditionally, egalitarianism in police corps has particularly focused on promoting anti-racist attitudes. As Thompson, Fleming and Byran pointed out two decades ago (1996: 114): "There are now anti-racist pressure groups in the police force (...) the establishment of anti-racist pressure groups can 
be accounted for by the concern for addressing the negative image these groups (police) inspired among black and ethnic minority communities. Motivated by the need to change their public image and in the hope of recruiting more black and minority members to their numbers, public services and other national bodies established anti-racist or racism awareness slogans". However, the goal must be the eradication of all kinds of discrimination, since it is reductionist to think of types of inequity in a vacuum. Racist language has points of intersection with sexist language, as it does with other kinds of biased language which discriminates on the basis of class, age, ability, or race. Obviously, the use of discriminatory language and cultural stereotyping will have negative effects on relationships between police and the community, and therefore on the police function. Besides, media reporters tend to use police descriptors in cases with media impact, and discriminatory terms can be echoed if taken from a police source.

\section{Research Question}

Is it feasible to instruct trainee police officers in an ESP course to detect instances of discriminatory language, and produce their own ESP professional discourse in a non-discriminatory way?

\section{Educational Objectives}

Knowledge: To gain an understanding of the cultural and social impact of language, both mother tongue and foreign/second languages (Critical Language Awareness).

Attitude: To enhance empathy towards minority groups. To deal with diversity constructively as a phenomenon in today's societies.

Skills: To discuss questions of identity in a police environment. To distinguish between equal language treatment and differential language treatment in 'protected grounds' (European Union Agency for Fundamental Rights, 2013).

\section{Method}

Trainee police officers in English class (level B1) in the Spanish National Police Academy, located at the Avila Campus of the University of Salamanca, brainstorm their own mother tongue experience regarding the need for production of language neutral as to group membership (Jankowicz 2005).

'Use of English' guidelines are elicited after this lead-in, and completed with the following input to compose a decalogue:

AVOID (Hellinger, 2011):

1. False generics, with 'man' used to mean both men and women (business manager instead of businessmen, chairperson rather than chairman, police officer instead of policeman, firefighter in place of fireman), or compounds with 'man', which can be perceived as exclusive (manufactured rather than manmade, workforce instead of manpower, to operate instead of to man). These terms foster the expectation that only men can fulfil the jobs. Gender inclusive language does not exclude one gender nor demean their status.

2. Phrases that reinforce invisibility of the out-groups (average person in place of man in the street, intellectual instead of man of letters, best person for the job rather than best man for the job).

3. Sex role stereotyping, occupational titles, which convey assumed gender or class norms (cleaning lady, charwoman, groundsman, delegates and their wives). It is important to seek a balanced and fair representation of men and women in language. 
4. Asymmetrical gender-marking or extra visibility of difference (author rather than authoress, writer in place of lady writer, flight attendant instead of air hostess), where explicit gendermarking is not used in parallel male-specific or neutral contexts. 'Lady' should only be used when 'gentleman' would be appropriate for a male in the same situation. A stem word, usually for the male, with a gender-marked suffix (-ess, -ette, -trix, -ienne) conveys the idea that women are deviations from a male 'norm' and distracts attention from the occupation itself. Remove specification: irrelevant, gratuitous gender descriptions perpetuate the outdated attitude that women are to be considered first as female and second as persons of talent.

5. Trivialising language and paternalism towards less powerful groups (she's done an amazing job instead of she's done an amazing job for a person in a wheelchair). It stereotypes people from certain groups as being dependent and childlike, compared with members of a dominant group who are depicted as inherently benevolent and self-reliant. Avoid terms like dear, love, sweetie, for women, or gran for an older person, as well as undue emphasis on a woman's family roles: the officer won a medal rather than the officer mother of three won a medal.

6. Bias in favour of the prevailing culture (first name in place of Christian name, a professor rather than a Chinese professor). Ethnic and racial slurs: discriminatory humour and derogatory labels (nigger, paki). Minority groups lack the power to define themselves. Often the labels by which they are known have been imposed on them. This is not acceptable in a multi-cultural environment. Derogatory language can translate into discriminatory decisions and practices.

7. The use of discriminatory language and concepts relating to old age: older people in place of geriatrics, elderly person instead of old person.

8. Negative depictions of those with genetic conditions (a person with AIDS, instead of an AIDS victim/sufferer), which emphasise the disability over the person (visually impaired in place of blind). Such terms imply powerlessness and dehumanise the individual. Instead, highlight their personhood, put people first (a child with Down syndrome, rather than a Down syndrome child), subsuming the characteristic into a much wider life experience.

9. Historical generalisations and clichés: Women's historical contributions are commonly overlooked through phrases, which neglect their role: forefathers or founding fathers should be replaced by ancestors and pioneers.

10. Marital status discrimination: Terms as married or defacto spouse, while recognising changes in norms to include non-married partners, only legitimate those relationships that can be sanctioned by marriage. The term partner avoids these problems and does not take for granted sexual orientation. The titles 'Miss' and 'Mrs' not only identify the person addressed as a woman, but also provide information on marital status, while the male equivalent ' $\mathrm{Mr}$ ' does not. The use of 'Ms' can help solve this.

In the second stage, trainee law enforcers are provided with practical examples and in pairs try to spot biased language:

The finishing plant was the scene of a confrontation today when two ladies from the morning shift accused a foreman of sexual harassment. Marta Maria Valdez, a Hispanic inspector, and Margaret Sawyer, an assembly-line worker, accused Mr. Engerrand of making suggestive comments. Mr. Engerrand, who is 62 years old and an epileptic, denied the charges and said he thought the girls were trying to cheat the company with their demand for a cash award (Ober, 2008: 107).

In the text, the women are referred to as ladies and girls, although it is unlikely that the men in the company are referred to as gentlemen and boys. The term foreman (and all other -man occupational titles) has a sexist connotation. The two women are identified by their first and last names, without personal titles, whereas the man is identified by a personal title and last name only. Valdez's ethnicity, Engerrand's age, and Engerrand's disability are expressed, although they are irrelevant to the situation.

Afterwards, students revise the following sentences and rephrase them to eliminate discriminatory language (Ober, 2008: 115):

a. The mayor opened contract talks with the union representing local policemen. 
b. While the salesmen are at the convention, their wives will be treated to a tour of the city's landmarks.

c. Our company gives each foreman the day off on his birthday.

d. Our public relations director, Aurelia Gordon, will ask her young secretary, Teresa Moretti, to take notes during the president's speech.

e. Both Dr. Marcos and his assistant, Terry Derek, attended the new-product seminar.

Pair discussion complements the activity with oral practice. Students subsequently draw up a glossary of prejudiced terms and their unbiased equivalents, which is meant to be an ongoing activity throughout the year, as more terms are added to the list.

In the third stage, in teams, trainee officers check on the Internet different guidelines to nondiscriminatory language issued by administrations, institutions and associations, and compare them. They spot similarities and differences according to country, type of institution (university, union, governmental agency...) and year of publication. They also gather the different terms proposed in the various sources for the same word to avoid, and discuss the best option. As follow-up tasks for group work, they establish a comparison between three anti-discrimination laws from different Englishspeaking countries, and contact electronically foreign police departments and stations to collect samples and authentic materials related to tackling this issue in real life police situations.

Some grammar and usage points are revised with a focus on non-discriminatory language, as they arise in the texts:

1. Use of personal pronouns: He, his, him and himself should refer only to a male person, as inaccuracies arise when they are used generically to substitute for a neutral third person singular pronoun. Cumbersome expressions such as he and she, she and he, she/he or s/he can be avoided rewriting the sentence in the plural, with they, their, them and themselves. Instead of the sergeant will display his timetable on his office door, sergeants will display their timetables on their office doors; rather than each constable is responsible for material on loan to him, constables are responsible for material they borrow. It is not acceptable to add the disclaimer that all masculine nouns and pronouns are to be taken as referring to both females and males.

2. Titles of address, word order and listing names: When writing to someone whose title, first name, surname or sex is unknown, the traditional use of Dear Sir as a generic salutation should be replaced by Dear Sir/Madam, Dear Madam or Sir, Dear Manager... When listing names, use alphabetical order of surnames except where order of seniority is more important. Vary the order of listing pairs when the customary way reflects stereotyped views of status (not always men and women, boys and girls). There should be consistency in the way all parties mentioned are addressed: contact Superintendent Smith or his secretary Jane Brown should be replaced by contact Superintendent Smith or Ms (Miss or Mrs) Jane Brown, secretary.

3. Revision of passive voice: the passive voice is a common resource when framing phrases that avoid discriminatory language constructions (Jankowicz 2005). Expressions such as he must return it by the due date should be replaced by it must be returned by the due date.

4. Revision of relative pronouns: anyone who wants his work evaluated should be replaced by anyone wanting their work evaluated (or those who want their work evaluated).

\section{Conclusions}

According to Ober (2008: 107), "nondiscriminatory language treats everyone equally, making no unwarranted assumptions about any group of people". Therefore, it is a guarantee that police officers will perform their duties more objectively. An ESP (law enforcement) syllabus should include guidelines and develop strategies to acquaint students with the discriminatory power of the foreign 
language being learned and to offer alternative unbiased wordings. Other ESP areas aimed at collectives in contact with citizens, especially civil servants, would also benefit from this approach.

Beyond the linguistic benefits, this methodology creates a positive atmosphere in the classroom, encourages broad research and provides relevant input for police professionals, linking the classroom with authentic materials and real life.

Language both shapes and reflects social reality, and the equality agenda can be strengthened if the language is toned down. What was acceptable in language decades ago is no longer tolerated for effective democratic citizenship. Appropriate training and awareness-raising activities allow trainee officers to produce discourse sensitive to difference, and have beneficial results in building up their linguistic proficiency addressed to their professional performance.

To sum up, applying strategies to detect instances of discriminatory language in the ESP law enforcement syllabus improves students' motivation, self-awareness and self-confidence, builds relationships, involves learners effectively in their own learning process and, undoubtedly, leads students to produce their own ESP professional discourse in a non-discriminatory way.

\section{References}

Davies, A. (2007). An Introduction to Applied Linguistics: From Practice to Theory Edinburgh: Edinburgh University Press.

European Union Agency for Fundamental Rights. (2013). Fundamental Rights-based Police Training - A Manual for Police Trainers. Luxembourg: Publications Office of the European Union.

European Parliament \& Office for Official Publications of the European Communities. (2000). Charter of Fundamental Rights of the European Union. Luxembourg: Office for Official Publications of the European Communities.

Hellinger, M. (2011). "Guidelines for Non-Discriminatory Language Use”. In R. Wodak, B. Johnstone \& P. E. Kerswill (eds.), The SAGE Handbook of Sociolinguistics (pp. 565-582). London: SAGE.

Hughes, G. (2007). Political Correctness: A History of Semantics and Culture. Oxford: WileyBlackwell.

Jankowicz, A.D. (2005). Business Research Projects. London: Thomson.

Nguyen, T. (2007). Political Correctness in the English Language. Norderstedt: Grin Verlag.

Ober, S. (2008). Student Achievement Series: Fundamentals of Contemporary Business Communication. Boston: Houghton Mifflin.

Thompson, L., Fleming, M. and Byram, M. (1996). "Languages and language policy in Britain”. In M. L. Herriman \& B. Burnaby (eds.), Language Policies in English-dominant Countries: Six Case Studies (pp. 99-121). Clevedon: Multilingual Matters. 